\title{
Structure elucidation, anticancer and antioxidant activities of a novel polysaccharide from Gomphus clavatus Gray
}

\author{
XIANG DING, YILING HOU, YUANXIU ZHU, PANPAN WANG, LEI FU, HONGQING ZHU, \\ NAN ZHANG, HANG QIN, WEI QU, FANG WANG and WANRU HOU \\ Key Laboratory of Southwest China Wildlife Resources Conservation, College of Life Sciences, \\ China West Normal University, Nanchong, Sichuan 637009, P.R. China
}

Received December 2, 2014; Accepted April 2, 2015

DOI: $10.3892 /$ or.2015.3921

\begin{abstract}
A novel heteropolysaccharide from the fruiting bodies of Gomphus clavatus Gray was isolated through Sephadex G-200 and DEAE-cellulose columns. The Gomphus clavatus Gray polysaccharide (GCG-1) was mainly composed of $\beta$-D-glucosepyranose ( $\beta$-D-Glu) and $\alpha$-D-galactopyranose ( $\alpha$-D-Gal) in a ratio of $3: 2$ and had a molecular weight of $\sim 50,000 \mathrm{Da}$. The structure of GCG-1 was investigated by a combination of total hydrolysis, gas chromatography-mass spectrometry, methylation analysis, nuclear magnetic resonance spectroscopy and infrared spectra. The results indicated that GCG-1 had a backbone of $(1 \rightarrow 4)-\beta$-D-glucosepyranose residues with branches at O-6 and the branches consisted of two with $(1 \rightarrow 3)$ - $\alpha$-D-galactopyranose residue. Antioxidation test in vitro showed that it possessedstrong free radical scavenging activity, which may be comparable to vitamin $\mathrm{C}$ and butylated hydroxytoluene. GCG-1 also induced the apoptosis of HepG-2 cells and affected the mRNA expression of various housekeeping genes in the HepG-2 cells. The results indicated that Gomphus clavatus Gray may be an ideal sources for antioxidant and anticancer agents.
\end{abstract}

\section{Introduction}

Mushrooms are a valuable part of a balanced nutrition. The use of mushrooms for food as well as for medicine is deep-rooted in most cultures. Many mushrooms contain healthy micronutrients, vitamins and mineral nutrients. Fungal polysaccharide is a type of active organic compound that is found in medicinal fungi, fruiting bodies and mycelium (1). Polysaccharides are

Correspondence to: Professor Yiling Hou, Key Laboratory of Southwest China Wildlife Resources Conservation, College of Life Sciences, China West Normal University, 1 Shida Road, Nanchong, Sichuan 637009, P.R. China

E-mail: starthlh@126.com

Key words: polysaccharide structure, anticancer activity, antioxidant activity, Gomphus clavatus Gray polymeric carbohydrate molecules composed of long chains of monosaccharide units bound together by glycosidic linkages and upon hydrolysis yield the constituent monosaccharides or oligosaccharides. They range in structure from linear to highly branched. Polysaccharides are often quite heterogeneous, containing slight modifications of the repeating unit. Depending on the structure, these macromolecules can have properties that are distinct from their monosaccharide building blocks. They may be amorphous or even insoluble in water (2). Recently, an increasing number of fungal polysaccharides have been reported to exhibit a variety of biological activities, including immunostimulatory, antitumor and antioxidant properties (3-8).

Gomphus clavatus Gray grows in Xiaojin Country of Sichuan Province in China at an elevation of 3,770 meters. A novel heteropolysaccharide was isolated from the fruiting bodies of Gomphus clavatus Gray through Sephadex G-200 and DEAE-cellulose columns. Its chemical structure and antioxidant and anticancer activities were characterized for the first time. Overall, Gomphus clavatus Gray may be an ideal source of antioxidant and anticancer agents.

\section{Materials and methods}

Chemicals. The fresh fruiting bodies of Gomphus clavatus Gray were collected in Xiaojing Country of Sichuan Province, China, and were authenticated by Professor Zhirong Yang (College of Life Sciences, Sichuan University, Chengdu, China). The fruiting bodies of Gomphus clavatus Gray were crushed and stored at $4^{\circ} \mathrm{C}$ before being used in the Key Laboratory of Southwest China Wild Resources Conservation, School of Life Sciences, China West Normal University. Sephadex G-200 and DEAE-cellulose 52 were purchased from Sigma-Aldrich (Shanghai, China). Trifluoroacetic acid (TFA), standard monosaccharides and dextrans of different molecular weights (MWs) were purchased from Beijing Biodee Biotechnology Co., Ltd. (Beijing, China). All other reagents used were of analytical grade.

Extraction, purity and fractionation of the polysaccharides from Gomphus clavatus Gray. Dried and powdered Gomphus clavatus Gray (280 g) was precisely weighed and then extraction was carried out with 2,000 ml distilled water 
at $90^{\circ} \mathrm{C}$ for $6 \mathrm{~h}$. After extraction, the extractive was filtrated and then centrifuged at 10,000 rpm for $25 \mathrm{~min}$ in a high-speed centrifuge and subsequently concentrated in a vacuum. Then the supernatant was added with 3 volumes of $95 \% \mathrm{EtOH}$ to precipitate crude polysaccharides (GCG; $26.0 \mathrm{~g}$, recovery 9.3\%). The Sevag method was used for the deproteination (9), and the crude polysaccharides (10 g) were redissolved in $50 \mathrm{ml}$ of distilled water, and purified with a DEAE-cellose column (Tris- $\mathrm{HCl}, \mathrm{pH} 7.0,4.5 \times 50 \mathrm{~cm}, \mathrm{Cl}^{-}$) equilibrated with distilled water. The polysaccharides were fractionated and eluted stepwise with $\mathrm{NaCl}$ solutions at different concentrations $(0,0.1$, $0.2,0.3,0.4,0.5$ and $1.0 \mathrm{~mol} / 1 \mathrm{NaCl})$. The eluate was monitored by the phenol-sulfuric acid method (10). The pure water elution was concentrated and purified on a Sephadex G-200 column $(2.6 \times 60 \mathrm{~cm})$. The resulting product was concentrated and passed through a 7-kDa membrane for $48 \mathrm{~h}$ to eliminate small-molecular compounds. The Gomphus clavatus Gray polysaccharide, named GCG-1, was obtained by the above processes and then lyophilized. The yield rate of GCG-1 was $0.11 \%(0.300 \mathrm{~g})$ form the starting material.

Measurement of the molecular weight (MW) of GCG-1. The MW of the polysaccharide fraction was identified by high-performance gel permeation chromatography (HPGPC) (11). An aliquot (5 mg) of the dry sample was dissolved in $10 \mathrm{ml}$ of double-distilled water and filtered through a membrane filter $(0.22-\mu \mathrm{m})$. The calibration curve was prepared from the standard T-series Dextran (T-500, T-110, T-70, T-40 and T-10). The data were analyzed using GPC software (Millennium 32 software).

Monosaccharide composition analysis of GCG-1. The polysaccharide GCG-1 (6.0 mg) was hydrolyzed with $2 \mathrm{M}$ trifluoroacetic acid (TFA) at $110^{\circ} \mathrm{C}$ for $8 \mathrm{~h}$ (12). After removing the excess acid with methyl alcohol $(\mathrm{MeOH})$ when the hydrolysis was completed, the samples were dissolved with distilled water for analyzing the monosaccharide composition. One part of the hydrolysate $(2.0 \mathrm{mg})$ was used for thin layer chromatography analysis (TLC) with developing solvent [acetoacetate-pyridine-ethanol-water solution (8:5:1.5:1)] and developer system (85\% phosphoric acid solution $140 \mathrm{ml}$ containing $8 \mathrm{ml}$ diphenylamine, $8 \mathrm{~g}$ aniline) (13). The other $(2.0 \mathrm{mg})$ was dissolved in pyridine $(0.2 \mathrm{ml})$. The derivatization reaction was initiated by addition of hexamethyldisilazane $(0.2 \mathrm{ml})$ and trimethylchlorosilane $(0.2 \mathrm{ml})$ (14). The resulting supernatant was examined by chromatographymass spectrometry (GC-MS) on a column of Rtx-5sil MS (5\% phenylmethylsiloxane $30 \mathrm{~mm} \times 0.25 \mathrm{~mm} \times 0.25 \mu \mathrm{m}$ ) at a temperature program of $50-230^{\circ} \mathrm{C}$ with a rate of $2^{\circ} \mathrm{C} / \min (15,16)$.

Methylation analysis. The polysaccharide was methylated using methyliodide (MeI) according to the method of Hakomori (16). The completeness of methylation was confirmed by the disappearance of the hydroxyl absorption in infrared (IR) spectrum at $3,400 \mathrm{~cm}^{-1}$. The permethylated product was depolymerized with $90 \%$ formic acid at $100^{\circ} \mathrm{C}$ for $4 \mathrm{~h}$ and further hydrolyzed with $2 \mathrm{M}$ TFA at $100^{\circ} \mathrm{C}$ for $8 \mathrm{~h}$. The resulting products were derivatized using the derivatization reagent and analyzed by GC-MS.
UV and IR spectral analysis. GCG-1 was tested in UV light from 200 to $400 \mathrm{~nm}$. FT-IR spectra of the sample were measured by grinding a mixture of polysaccharide with dry $\mathrm{KBr}$ and then pressing in a mold. Fourier transform IR spectra of the GCG-1 film were collected using a Thermo Nicolet 6700 spectrometer operating in the range of $400-4,000 \mathrm{~cm}^{-1}$ at a resolution of $4 \mathrm{~cm}^{-1}$.

Nuclear magnetic resonance (NMR) experiment. The polysaccharide was dissolved in deuteroxide accompanied by ultrasonic wave processing for $30 \mathrm{~min}$. Then the Varian Unity INOVA 400/45 was used to perform the ${ }^{1} \mathrm{H}$ NMR spectra (GCG-1, $80 \mathrm{mg}$ ) and ${ }^{13} \mathrm{C}$ NMR spectra (GCG-1, $40 \mathrm{mg}$ ) analysis with tetramethylsilane as internal standard.

Determination of 1,1-diphenyl-2-picrylhydrazyl-free $\left(D P P H^{-}\right)$radical scavenging activity of $G C G-1$. The $\mathrm{DPPH}^{-}$ radical scavenging activity of the polysaccharide sample was measured according to the method described by Braca et al $(17,18)$. Antiradical activity was measured by a decrease in absorbance at $517 \mathrm{~nm}$ of a solution of purple-colored DPPH in methanol brought about by the sample. Absorbance at $517 \mathrm{~nm}$ was determined after 30 min using a UV-visible spectrometer; a lower absorbance of the reaction mixture indicated higher free radical scavenging activity. The capability to scavenge the DPPH radical was calculated using the following equation: Scavenging effect $(\%)=(1-$ A sample/A control $) \times 100$, where A control is the absorbance of the control $\left(\mathrm{DPPH}^{-}\right.$solution without sample), A sample is the test sample ( $\mathrm{DPPH}^{-}$solution plus test sample or positive control). Vitamin C (Vc) and butylated hydroxytoluene (BHT) were used as positive control.

Scavenging activity of the 2,2'-azino-bis(3-ethylbenzthiazoline-6-suphonic acid) diammonium (ABTS) radical of $G C G-1$. ABTS radical scavenging activity of the polysaccharide extracts and fractions was measured by the ABTS cation decolorization assay as described by Auddy et al $(19,20)$. The ABTS radical cation $\left(\mathrm{ABTS}^{+}\right)$was produced by reaction of $7 \mathrm{mM}$ stock solution of ABTS with $2.45 \mathrm{mM}$ ammonium persulphate (APS) and allowing the mixture at room temperature in the dark for $16 \mathrm{~h}$. Then $2 \mathrm{ml}$ of various concentrations of the sample and $2 \mathrm{ml}$ of $\mathrm{ABTS}^{+}$radical solution $(0.7 \mathrm{mM})$ were added. The absorbance was measured immediately at $734 \mathrm{~nm}$. A control reaction was carried out without the extract. The percentage of scavenging of hydrogen radicals was calculated as follows: Scavenging effect $(\%)=[1$ - (A sample - A sample blank)/A control] x 100, where A control is the absorbance of the control group in the $\mathrm{ABTS}^{+}$radical generation system, A sample is the absorbance of the test group and A sample blank is the absorbance of the samples only. Vc was used as a positive control.

Cell lines and culture. PC12 cells [American Type Culture Collection (ATCC) USA] were maintained in Dulbecco's modified Eagle's medium (DMEM), which contained $10 \%$ fetal bovine serum (FBS) and antibiotics $(100 \mathrm{U} / \mathrm{ml}$ penicillin, $100 \mathrm{mg} / \mathrm{ml}$ streptomycin) at $37^{\circ} \mathrm{C}$ in a humidified atmosphere containing $5 \% \mathrm{CO}_{2}$. Human hepatoma G-2 cells were purchased from the North Sichuan Medical College, Institute of Biochemistry and Molecular Immunology and maintained 
in MEM (Gibco Co., Carlsbad, CA, USA) supplemented with 10\% FBS (Evergreen Biological Products Co., China), $100 \mathrm{U} / \mathrm{ml}$ penicillin, $100 \mu \mathrm{g} / \mathrm{ml}$ streptomycin and $\mathrm{pH} 7.4$ RPMI-1640 (all from Gibco Co.) at $37^{\circ} \mathrm{C}$ in a humidified atmosphere containing $5 \% \mathrm{CO}_{2}$.

Antioxidant activity assay. In the present study, $\mathrm{PC} 12$ cells were seeded into 96-well plates at a concentration of $5 \times 10^{4}$ cells $/ \mathrm{ml}$ using DMEM. After $24 \mathrm{~h}$, the PC12 cells were pretreated with GCG-1 for $2 \mathrm{~h}$ before $\mathrm{H}_{2} \mathrm{O}_{2}$ (300 mM solution) exposure for $1 \mathrm{~h}$. After the $\mathrm{H}_{2} \mathrm{O}_{2}$ was withdrawn, cells were then further incubated in the fresh medium for another $6 \mathrm{~h}$ at $37^{\circ} \mathrm{C}$. Then, Cell Counting Kit-8 (CCK-8) solution $(10 \mu \mathrm{l})$ was added to each well. After incubating for $4 \mathrm{~h}$, the absorbance measurement was determined at $450 \mathrm{~nm}$ using a Universal microplate reader (Bio-Rad, USA). The damage inhibitory effect was expressed as: Damage inhibitory effect $(\%)=\left[\left(\mathrm{A}_{\mathrm{s}}-\mathrm{A}\right)\right] /\left[\left(\mathrm{A}_{0}-\mathrm{A}\right)\right] \times 100 \%$, where $A_{s}$ is the absorbance in the presence of the sample and $\mathrm{H}_{2} \mathrm{O}_{2}, \mathrm{~A}_{0}$ is the absorbance of the control in the absence of the sample and $\mathrm{H}_{2} \mathrm{O}_{2}$, and $\mathrm{A}$ is the absorbance only in the presence of $\mathrm{H}_{2} \mathrm{O}_{2}$.

Quantitative RT-PCR detection of related gene expression. The HepG-2 cells were harvested after stimulation by various concentrations of GCG-1 for $4 \mathrm{~h}$. The total cellular RNA was extracted using TRIzol reagent and reverse-transcribed into cDNA using oligo $(\mathrm{dT})_{18}$ primers (both from Invitrogen, USA). Amplification of each target cDNA was performed in a cycler system (Bio-Rad). PCR products were quantified using SYBR-Green I and $\beta$-actin was used as an endogenous control to normalize expression levels. The relative expression abundance was calculated by the following formula: Relative expression abundance $=$ moles of detected $\mathrm{mRNA} / \mathrm{moles}$ of $\beta$-actin mRNA.

Statistical analysis. All data are presented as means \pm standard deviation (SD) of three replications. Statistical analyses were performed using the Student's t-test and one-way analysis of variance. Values of $\mathrm{P}<0.05$ were considered to indicate statistically significant findings.

Statement of the use of humans and experimental animals. The present study was carried out on humans following the international and national regulations. The study also followed internationally recognized guidelines on animal welfare, as well as local and national regulations.

\section{Results and Discussion}

Extraction, purity and composition of polysaccharides. The crude polysaccharide, named GCGP, was obtained from the fruiting bodies of Gomphus clavatus Gray with a yield of 9.3\%. After fractionation with Sephadex G-200 and DEAE-cellulose 52 column chromatography, $200 \mathrm{mg}$ of GCG-1 was obtained from the $0.1 \mathrm{M} \mathrm{NaCl}$ eluate. GCG-1 was eluted from gel-filtration chromatography on Sephadex G-200 column and was detected by the phenol-sulfuric acid assay as a single peak and it had the same optical rotation: $[\alpha]^{20}{ }_{\mathrm{D}}-11.4^{\circ}$ (c 0.5 , water) with different low concentration of ethanol using HK7-SGW-1 automatic optical polarimeter. HPGPC of the polysaccharide fraction showed that each fraction was represented by a broad and symmetrical peak on the chromatograms. The dextran standards were used to create a calibration curve for elucidating the molecular weight of GCG-1. The average molecular weight of GCG-1 was $\sim 50,000 \mathrm{Da}$ and the polydispersity was 3.77 (Fig. 1A). The composition analysis of polysaccharides is an important step to control the quality and obtain basic information about polysaccharides. In the present study, the GCG-1 polysaccharide sample was hydrolyzed with TFA and then the component monosaccharides were analyzed by TLC. It was shown that the GCG-1 polysaccharides had a composition of D-glucose and D-galactose. GCG-1 was in good agreement with the D-configuration monosaccharides according to the GC-MS analysis.

Structure elucidation of GCG-1. The IR spectrum of the sample showed that the absorption was very obvious at $>3,000 \mathrm{~cm}^{-1}$, which was caused by the stretching vibration and angular vibration of $\mathrm{O}-\mathrm{H}$ linkage. The intensity of bands $\sim 3,416 \mathrm{~cm}^{-1}$ in the IR spectrum (Fig. 1B) was due to the hydroxyl stretching vibration of the polysaccharide and as expected they were broad. The absorption peak at $2,932 \mathrm{~cm}^{-1}$ was $\mathrm{C}-\mathrm{H}$ stretching vibration absorption peak of GCG-1, and the bands in the region of $1,653 \mathrm{~cm}^{-1}$ were due to associated water (21). The strong absorption bands at $1,404 \mathrm{~cm}^{-1}$ were due to $\mathrm{C}-\mathrm{H}$ bending vibration and the bands in the region of 400-702 $\mathrm{cm}^{-1}$ were due to $\mathrm{C}-\mathrm{H}$ rocking vibration. The strong absorption bands at 1,046 and $1,077 \mathrm{~cm}^{-1}$ in the range of $1,200-1,000 \mathrm{~cm}^{-1}$ in the IR spectrum suggested that the monosaccharides in GCG-1 had a pyranose-ring (22). Moreover, the characteristic absorption at $917 \mathrm{~cm}^{-1}$ indicated $\alpha$-configurations (23), which was in good agreement with the anomeric proton signals at $\delta 4.965, \delta 4.914$ and $\delta 4.842$ in the ${ }^{1} \mathrm{H}$ NMR $(400 \mathrm{MHz})$ spectrum (Fig. 2A). $\delta 4.674$ was the hydrogen signal of water. The signals at $\delta 3.180-4.392$ are the signal peaks of remaining proton which were mostly formed by a number of signal peaks which overlapped.

The resonances in the region of 101-103 ppm in the ${ }^{13} \mathrm{C}$ NMR (400 MHz) spectrum of GCG-1 were due to the anomeric carbon atoms of $\beta$-D-glucosepyranose ( $\beta$-D-Glup) and $\alpha$-D-galactopyranose ( $\alpha$-D-Galp) (24). Signals at $\delta 103.657$ could be attributed to C-1 of $\rightarrow 3)-\alpha-D-G a l-(1 \rightarrow$; $\delta 103.026$ to $\mathrm{C}-1$ of $\alpha$-D-Gal- $(1 \rightarrow ; \delta 102.925$ to C- 1 of $\rightarrow 4)-\beta-D-$ Glu- $(1 \rightarrow$ (Fig. 2B) (Table I).

The methylated products of GCG-1 were hydrolyzed with acid, converted into alditol acetate and analyzed by GC-MS. Experiment data were collected and are listed in Table II. The information in MS showed that fragment ion peaks were consistent with data of D-configuration monosaccharide fragment ion peaks which can be concluded that galactose and glucose residues had D configuration, respectively. Methylation analysis for GCG-1 proved that the $\alpha$-D-galactopyranose residues were 2,4,6-tri-substituted and 2,3,4,6-tetra-substituted, the $\beta$-D-Glup) residues were 2,3-bis-substituted and 2,3,6-trisubstituted (Table II and Fig. 3). Results of the methylated linkage analysis of GCG-1 indicated that the branched residue was $(1 \rightarrow 4,6)$-linked- $\beta$-D-glucosepyranose and also revealed that $(1 \rightarrow 4)$-linked- $\beta$-D-glucosepyranose possibly formed the backbone structure. Residues of branch structures were terminated with $\alpha$-D-galactopyranose residues. The relative amounts of 

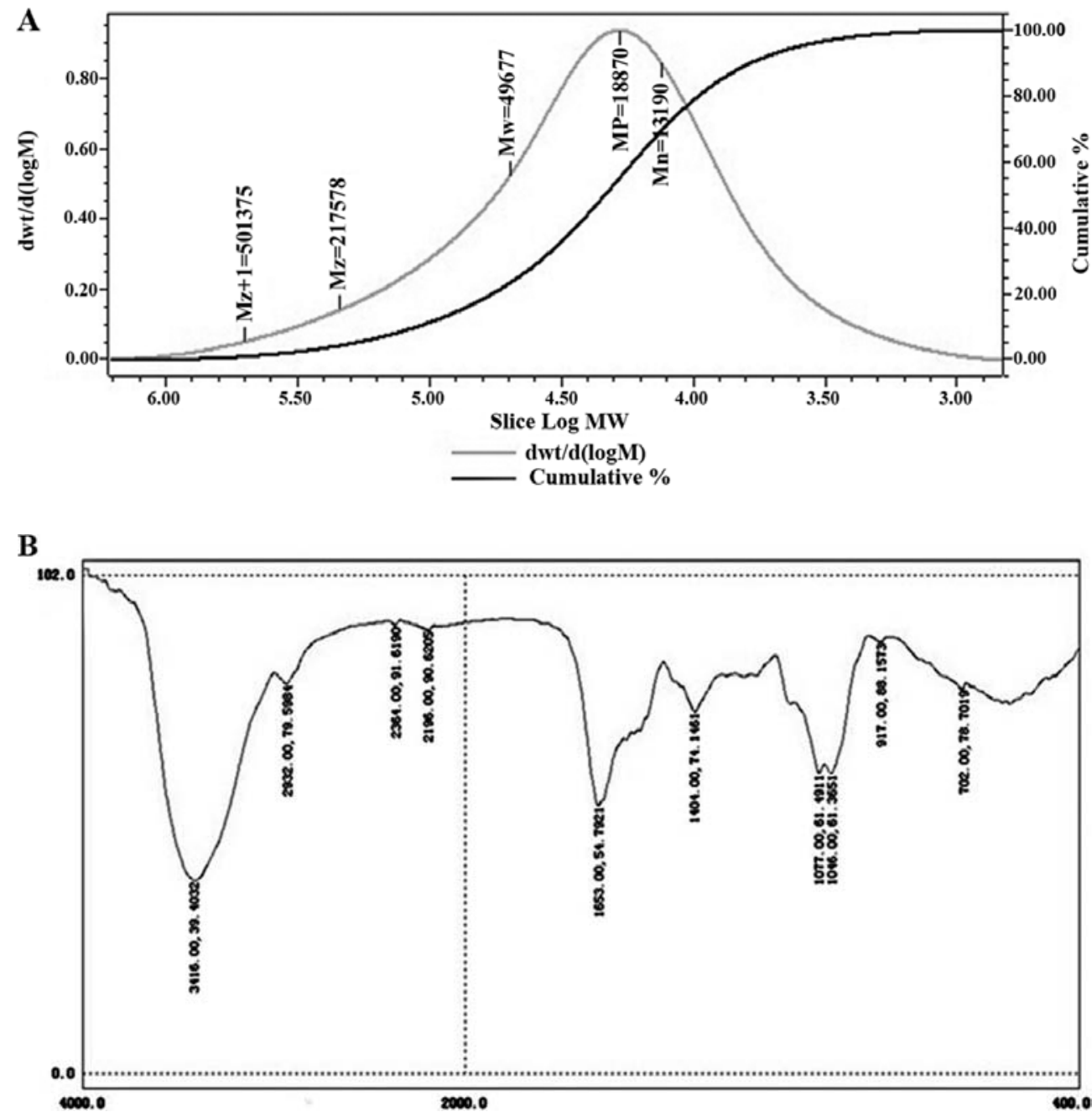

Figure 1. (A) Molecular weight determination spectrum of GCG-1 by HPGPC. (B) FTIR spectra of GCG-1. GCG-1, Gomphus clavatus Gray polysaccharide; HPGPC, high-performance gel permeation chromatography.

Table I. ${ }^{13} \mathrm{C}$ NMR chemical shift data $(\delta, \mathrm{ppm})$ for polysaccharide GCG-1.

\begin{tabular}{|c|c|c|c|c|c|c|}
\hline \multirow[b]{2}{*}{ Sugar residues } & \multicolumn{6}{|c|}{ Chemical shifts, $\delta$ (ppm) } \\
\hline & $\mathrm{C} 1$ & $\mathrm{C} 2$ & $\mathrm{C} 3$ & $\mathrm{C} 4$ & C5 & C6 \\
\hline$\rightarrow 4)-\beta$-D-Glu- $(1 \rightarrow$ & 102.925 & 65.234 & 66.840 & 69.585 & 73.406 & 75.650 \\
\hline$\rightarrow 4,6)-\beta-$ D-Glu- $(1 \rightarrow$ & 101.411 & 61.107 & 66.590 & 68.899 & 73.104 & 74.956 \\
\hline$\rightarrow 3)-\alpha-D-G a l-(1 \rightarrow$ & 103.657 & 60.110 & 67.543 & 70.424 & 74.184 & 76.034 \\
\hline$\alpha$-D-Gal-( $(1 \rightarrow$ & 103.026 & 60.806 & 67.221 & 70.093 & 73.519 & 75.952 \\
\hline
\end{tabular}

NMR, nuclear magnetic resonance; GCG-1, Gomphus clavatus Gray polysaccharide.

$(1 \rightarrow 4,6)$-linked- $\beta$-D-glucosepyranose indicated that approximate branch ratios could theoretically be $60 \%$, corresponding to an average two branching points at each three backbone residues. It was concluded that GCG-1 had a backbone of $(1 \rightarrow 4)-\beta$-D-glucopyranose residues which branch at O-6 based on the experimental results. The branches were mainly composed of two with $(1 \rightarrow 3)-\alpha$-D-galactopyranose residue. The predicted structure of the novel polysaccharide GCG-1 is shown in Fig 4.
Determination of $D P P H^{-}$radical scavenging activity of $G C G-1$. The decrease in absorbance of the $\mathrm{DPPH}^{-}$radical caused by antioxidants is due to the reaction between antioxidant molecules and radical progress which results in the scavenging of the radical by hydrogen donation. It is visually noticeable as a change in color from purple to yellow. GCG-1 exhibited a comparable antioxidant activity with that of standard ascorbic acid at varying concentrations tested. There was a dose-dependent increase in the percentage of 
$\mathbf{A}$
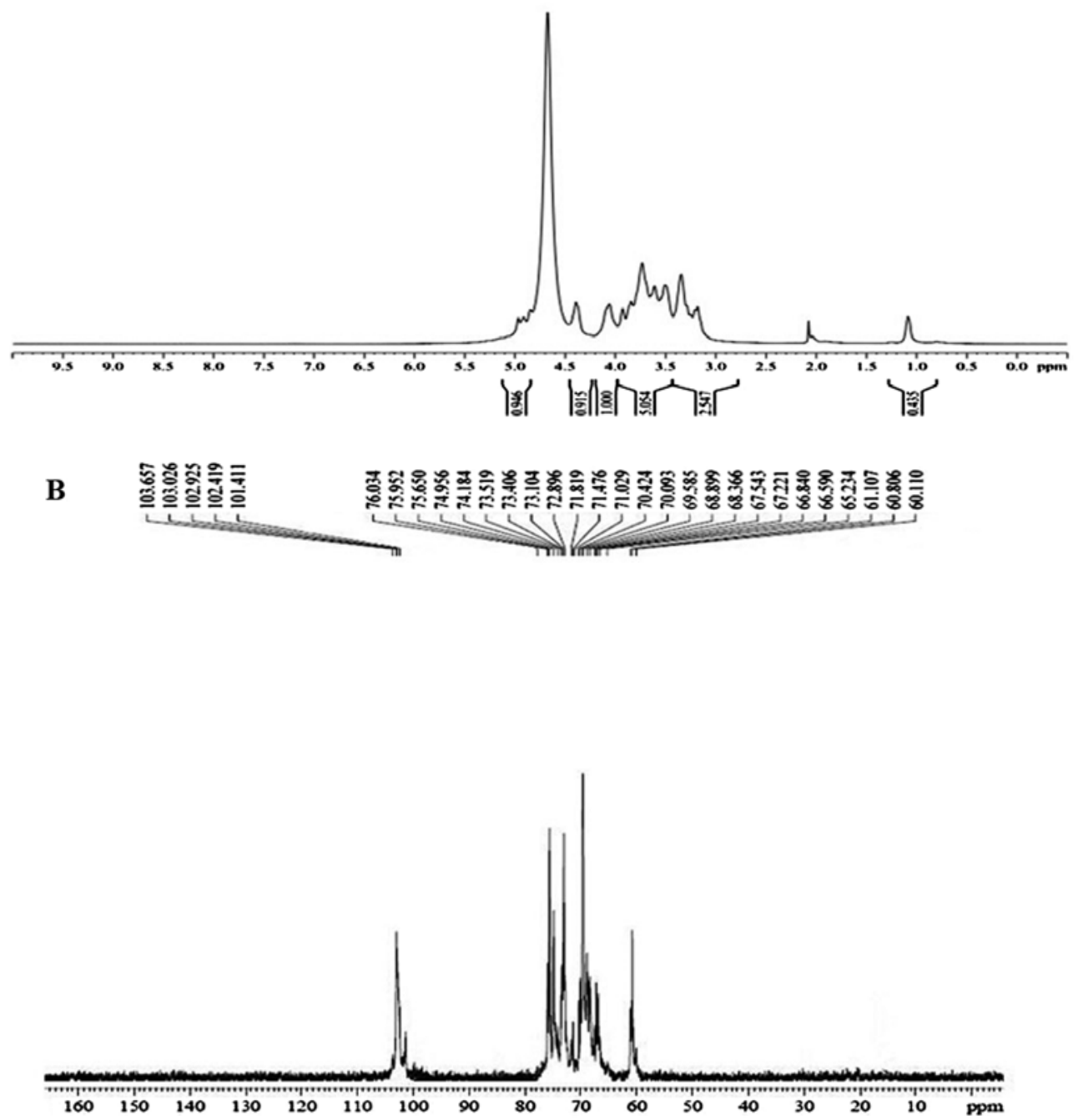

Figure 2. (A) The ${ }^{1} \mathrm{H}$ NMR spectra of GCG-1. (B) The ${ }^{13} \mathrm{C}$ NMR spectra of GCG-1. GCG-1, Gomphus clavatus Gray polysaccharide; NMR, nuclear magnetic resonance.

Table II. GC-MS results of the methylation analysis of GCG-1 .

\begin{tabular}{lll}
\hline Methylated sugar & Linkage & \multicolumn{1}{c}{$\mathrm{m} / \mathrm{z}$} \\
\hline $2,3,6-\mathrm{Me}_{3}-\mathrm{Glu}$ & $1,4-$ & $45,59,73,89,101,133,146,159,204,217,233$ \\
$2,3-\mathrm{Me}_{2}-\mathrm{Glu}$ & $1,4,6-$ & $45,59,73,88,103,117,133,147,159,175,205,217,232$ \\
$2,4,6-\mathrm{Me}_{3}-\mathrm{Gal}$ & $1,3-$ & $45,59,73,89,101,117,131,146,159,173,204,217,233$ \\
$2,3,4,6-\mathrm{Me}_{4}-\mathrm{Gal}$ & $\mathrm{T}-$ & $45,59,73,89,103,117,146,159,173,191,207,231$ \\
\hline
\end{tabular}

GC-MS, gas chromatography-mass spectrometry; GCG-1, Gomphus clavatus Gray polysaccharide.

antioxidant activity for all concentrations tested (Fig. 5). These results showed that the $\mathrm{IC}_{50}$ value of $\mathrm{GCG}-1$ for eliminating $\mathrm{DPPH}^{-}$radicals was $\sim 0.467 \mathrm{mg}^{-\mathrm{ml}^{-1}}$, which indicated that GCG-1 had a noticeable effect on scavenging the DPPH radical, particularly at high addition quantity. However, the inhibitory ability was lower than that of BHT and Vc.
Determination of $\mathrm{ABTS}^{+}$radical cation scavenging activity of $G C G-1$. The ABTS radical scavenging activity of GCG-1 was measured spectrophotometrically at $734 \mathrm{~nm}$. The results of antioxidant activity of GCG-1 are expressed as shown in Fig. 5B. Absorbance of the $\mathrm{ABTS}^{+}$radical cation was decreased dose-dependently, and the $\mathrm{IC}_{50}$ value of GCG-1 was 
A SI:85 Formula:C17H40O6Si3 CAS:55400-22-1 MolWeight:424 RetIndex:1819

CompName:Galactopyranose, 2,6-di-O-methyl-1,3,4-tris-O-(trimethylsilyl)- \$\$ 2,6-Di-O-methyl-1,3,4-tris-O-(trimethylsilyl)hexopyranose

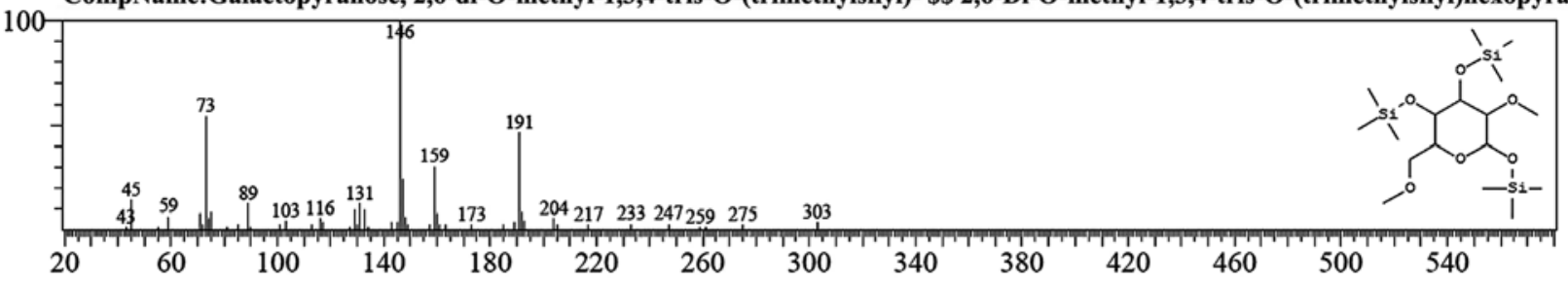

B SI:86 Formula:C17H40O6Si3 CAS:55449-69-9 MolWeight:424 RetIndex:1819

CompName:Galactopyranose,2,4-di-O-methyl-1,3,6-tris-O-(trimethylsilyl)-\$\$ 2,4-Di-O-methyl-1,3,6-tris-O-(trimethylsilyl)hexopyranose

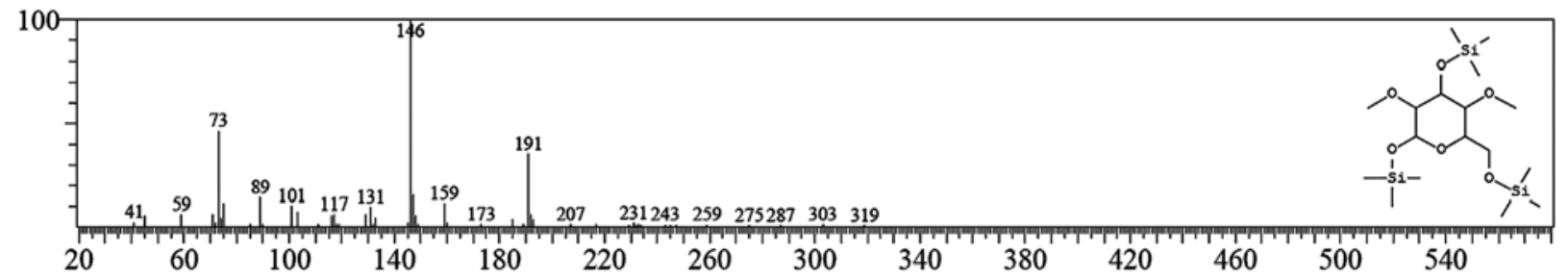

C SI:70 Formula:C17H40O6Si3 CAS:55400-21-0 MolWeight:424 RetIndex:1819

CompName:Glucopyranose, 3,6-di-O-methyl-1,2,4-tris-O-(trimethylsilyl)- \$\$ 3,6-Di-O-methyl-1,2,4-tris-O-(trimethylsilyl)hexopyranose

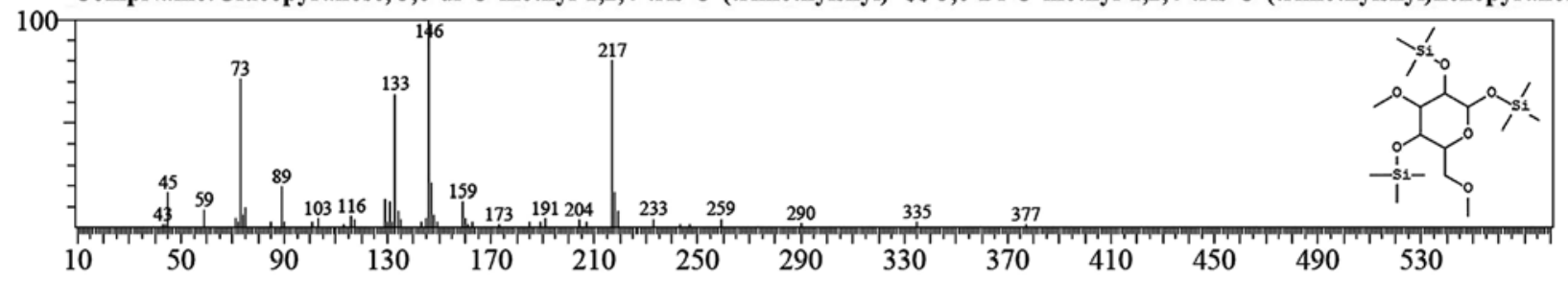

D SI:85 Formula:C17H40O6Si3 CAS:55400-17-4 MolWeight:424 RetIndex:1819

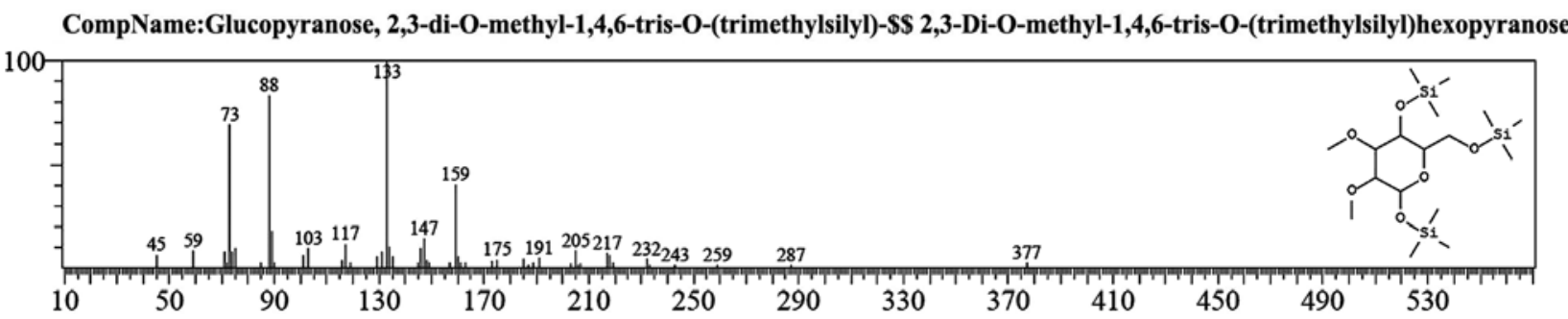

Figure 3. The GC-MS spectra of GCG-1. (A) The fragment ion peaks of 2,6-di-O-methyl-1,3,4-tris-O-(trimethylsilyl)-galactopyranose. (B) The fragment ion peaks of 2,4-di-O-methyl-1,3,6-tris-O-(trimethylsilyl)-galactopyranose. (C) The fragment ion peaks of 3,6-di-O-methyl-1,2,4-tris-O-(trimethylsilyl)glucopyranose. (D) The fragment ion peaks of 2,3-di-O-methyl-1,4,6-tris-O-(trimethylsilyl)-glucopyranose. GC-MS, gas chromatography-mass spectrometry; GCG-1, Gomphus clavatus Gray polysaccharide.

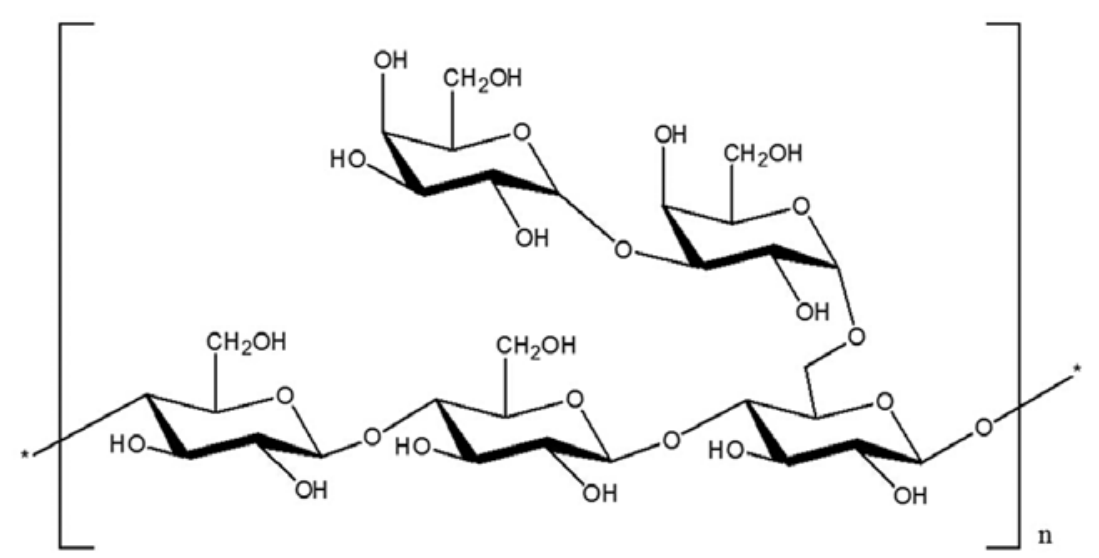

Figure 4. Predicted chemical structure of GCG-1. GCG-1, Gomphus clavatus Gray polysaccharide. 

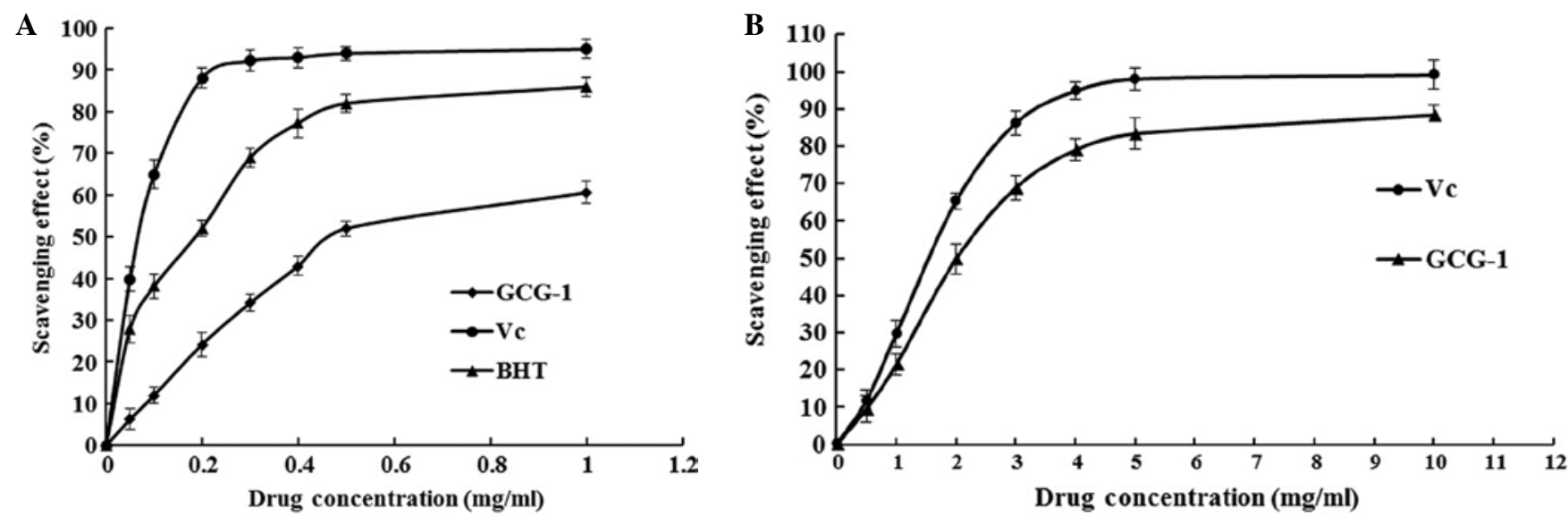

Figure 5. (A) DPPH- radical scavenging effect of GCG-1 from Gomphus clavatus Gray; (B) determination of ABTS ${ }^{+}$radical cation scavenging activity of GCG-1. GCG-1, Gomphus clavatus Gray polysaccharide.

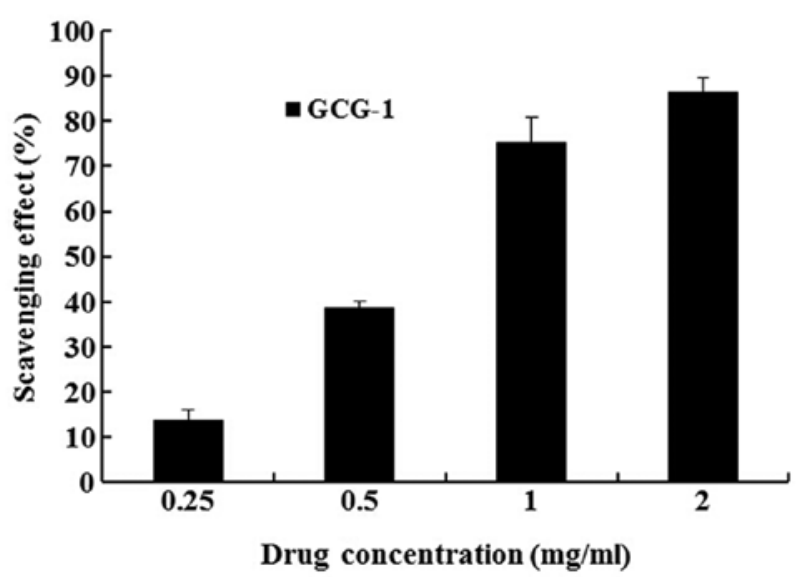

Figure 6. GCG-1 attenuates PC12 cell damage induced by hydrogen peroxide. GCG-1, Gomphus clavatus Gray polysaccharide.

$2.520 \mathrm{mg} \cdot \mathrm{ml}^{-1}$. However, the scavenging activity was lower than that of $\mathrm{Vc}$.

Antioxidant activity analysis of GCG-1 by $C C K-8$. In the CCK-8 experiments, we determined the protective effect of GCG-1 on PC12 cells from hydrogen peroxide $\left(\mathrm{H}_{2} \mathrm{O}_{2}\right)$-induced injury. After pretreatment with $0.25,0.5,1,2 \mathrm{mg}^{\circ} \mathrm{ml}^{-1}$ of GCG-1, the PC12 cells were protected from $\mathrm{H}_{2} \mathrm{O}_{2}(300 \mathrm{mM})$ injury in a dose-dependent manner, with cell viability rates of $13.8,38.5$, 75.2 and $86.3 \%$, respectively (Fig. 6). Thus, we confirmed that GCG-1 attenuates the injury on PC12 cells induced by $\mathrm{H}_{2} \mathrm{O}_{2}$.

Effect of GCG-1 on the morphology of human hepatoma HepG-2 cells. The 96-well plates were placed under an inverted microscope, and images recorded the changes in cell morphology for different concentrations of GCG-1 in order to measure the effect of GCG-1.GCG-1 exhibited high anticancer activity as observed from the cell morphology, examples are shown in Fig. 7.

GCG-1 affects the expression of mRNA expression of housekeeping genes in HepG-2 cells. Housekeeping genes are typically constitutive genes that are required for the mainte- nance of basic cellular function, and are expressed in all cells of an organism under normal and pathophysiological conditions. These genes tend to produce proteins at steady rates, and errors in their expression can lead to cell death. Quantitative RT-PCR results showed that GCG-1 affected the mRNA expression of various housekeeping genes in HepG-2 cells compared to the untreated cells (Table III).

Cyclin-dependent kinase inhibitor 2B (Cdkn2b) gene lies adjacent to the tumor-suppressor gene CDKN2A in a region that is frequently mutated and deleted in a wide variety of tumors (25). Adenomatous polyposis coli (APC) is classified as a tumor-suppressor gene which prevents the uncontrolled growth of cells resulting in cancerous tumors (26). The APC protein produced by the APC gene controls how often a cell divides, how it attaches to other cells within a tissue, or whether a cell moves within or away from a tissue thus determining whether a cell may develop into a tumor. Runtrelated transcription factor 3 (Runx3) gene encodes a member of the runt domain-containing family of transcription factors. A heterodimer of this protein and a $\beta$ subunit forms a complex that binds to the core DNA sequence 5'-PYGPYGGT-3' found in a number of enhancers and promoters, and can either activate or suppress transcription. IL-2 is a lymphokine that induces the proliferation of responsive $\mathrm{T}$ cells. In addition, it acts on various B cells, via receptor-specific binding (27), as a growth factor and antibody production stimulant (28). The protein is secreted as a single glycosylated polypeptide, and cleavage of a signal sequence is required for its activity (29). Quantitative RT-PCR results showed a significant upregulation in the levels of Apc, Cdkn2b, IL-2 and Runx 3 mRNA in the GCG-1-treated HepG-2 cells (Table III). Particularly the expression levels of APC and Runx3 mRNA in the HepG-2 cells increased 44.79 and 44.48 , respectively. Yet, the expression levels of Cdkn2b and IL-2 mRNA only increased 13.88 and 11.59, respectively.

The WW domain-containing oxidoreductase (WWOX) gene encodes a member of the short-chain dehydrogenase/ reductase (SDR) protein family. Expression of the encoded protein is able to induce apoptosis, while defects in this gene are associated with multiple types of cancer. Mdm2 is an important negative regulator of the p53 tumor suppressor. $\mathrm{Mdm} 2$ protein functions both as an E3 ubiquitin ligase that 

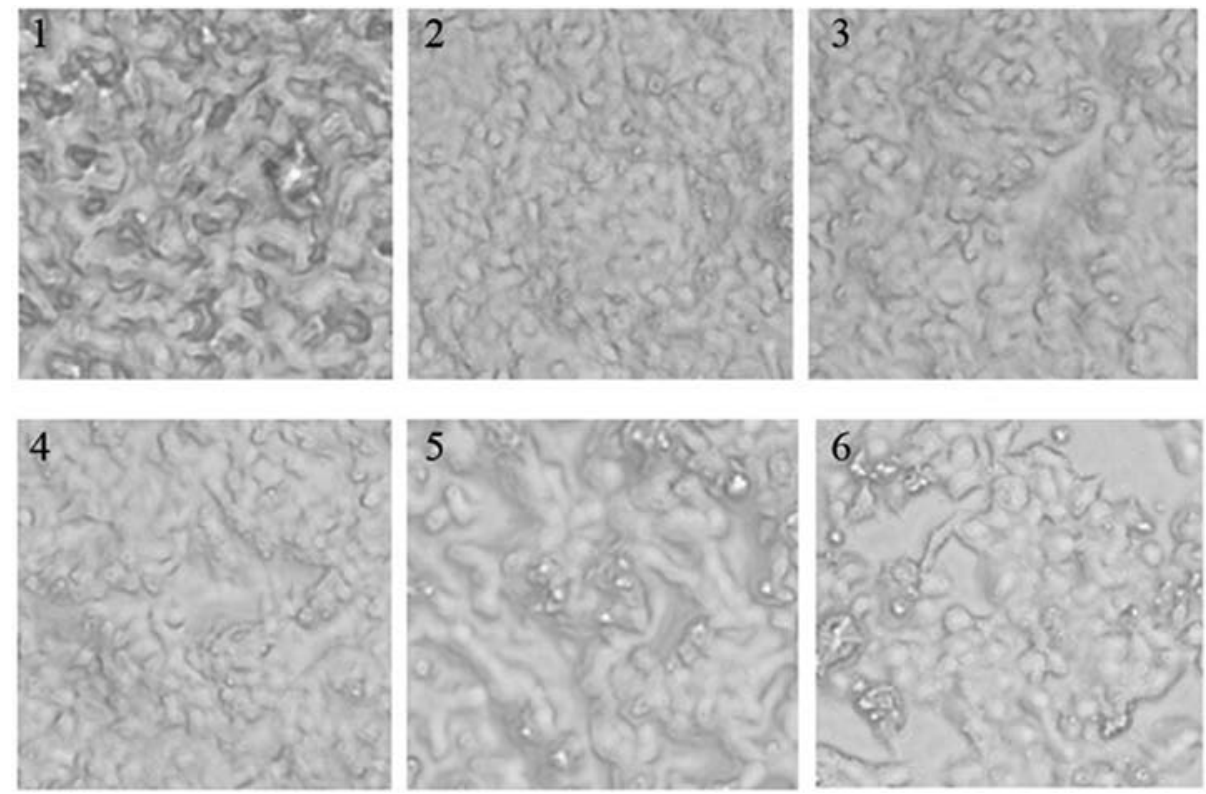

Figure 7. Effect of GCG-1 on the morphology of human hepatoma HepG-2 cells at concentrations of 0, 1.25, 2.5, 5, 10 and $20 \mu \mathrm{g} / \mathrm{ml}$ (images 1-6, respectively). GCG-1, Gomphus clavatus Gray polysaccharide.

Table III. mRNA expression of housekeeping genes in HepG-2 cells treated with GCG-1.

\begin{tabular}{lccccccc}
\hline Gene symbol & $\mathrm{a}$ & $\mathrm{b}$ & $\mathrm{c}$ & $\mathrm{d}$ & $\mathrm{e}$ & $\mathrm{f}$ & $\mathrm{g}$ \\
\hline APC & 30.55 & 12.39 & 28.02 & 6.91 & 5.49 & 0.02 & $44.79 \uparrow$ \\
RUNX3 & 37.00 & 18.84 & 34.48 & 13.37 & 5.48 & 0.02 & $44.48 \uparrow$ \\
CDKN2B & 33.30 & 15.14 & 32.46 & 11.35 & 3.80 & 0.07 & $13.88 \uparrow$ \\
IL2 & 38.27 & 20.11 & 37.69 & 16.58 & 3.54 & 0.09 & $11.59 \uparrow$ \\
WWOX & 29.25 & 11.09 & 36.91 & 15.80 & -4.71 & 26.08 & $26.08 \downarrow$ \\
MDM2 & 23.93 & 5.77 & 30.28 & 9.17 & -3.40 & 10.52 & $10.52 \downarrow$ \\
\hline
\end{tabular}

a, Ct of HepG-2 group; b, $\Delta$ Ct of HepG-2 group; c, Ct of HepG-2 group treated with GCG-1; d, $\Delta$ Ct of HepG-2 group treated with GCG-1; $\mathrm{e}, \Delta \Delta \mathrm{Ct} ; \mathrm{f}, 2^{-\Delta \Delta \mathrm{Ct}} ; \mathrm{g}$, up $(\uparrow)$ or down $(\downarrow)$ regulated ratio of gene expression. GCG-1, Gomphus clavatus Gray polysaccharide; APC, adenomatous polyposis coli; RUNX3, runt-related transcription factor 3; CDKN2B, cyclin-dependent kinase inhibitor 2B; WWOX, WW domain-containing oxidoreductase.

recognizes the N-terminal transactivation domain (TAD) of the p53 tumor suppressor and an inhibitor of p53 transcriptional activation. Quantitative RT-PCR results showed a significant reduction in the levels of MDM2 and WWOX mRNA in the GCG-1-treated HepG-2 cells (Table III), which were 26.08 and 10.52, respectively (Table III). Further research is ongoing to determine the bioactive principle(s) of GCG-1 responsible for its anticancer activity.

Inconclusion, according to the above results, it was concluded that the novel polysaccharide obtained from Gomphus clavatus Gray is a heteropolysaccharide, namely GCG-1. The purified polysaccharide prepared (GCG-1) was confirmed to be of high purity. The present study also showed that GCG-1 consisted of two monosaccharides, namely D-Glu and D-Gal in a ratio 3:2 by GC-MS. Structural study demonstrated that GCG-1 had a backbone of $(1 \rightarrow 4)-\beta$-D-glucopyranose residues which branch at O- 6 based on the experimental results. The branches were mainly composed of two with a $(1 \rightarrow 3)-\alpha-D$-galactopyranose residue. The purified polysaccharide prepared in the present study was confirmed to be of high purity. Antioxidation test in vitro showed that it possessed strong free radical scavenging activity, which may be comparable to Vc and BHT. In PC12 cells as determined by the antioxidant effect assay, we found that GCG-1 significantly attenuated PC12 cell damage caused by hydrogen peroxide. Antioxidation test in vitro showed that it possessed strong free radical scavenging activity, which may be comparable to Vc and BHT. Moreover, GCG-1 induced the apoptosis of HepG-2 cells and affected the mRNA expression of various housekeeping genes in the HepG-2 cells. Overall, Gomphus clavatus Gray may be one ideal sources for antioxidant and anticancer agents.

\section{Acknowledgements}

The present study was supported by the National Natural Science Foundation of China (31400016 and 31200012), the Application Foundation Project of Sichuan Province (2013JY0094), the Science and Technology Support Project 
of Sichuan Province (2014SZ0020 and 2014FZ0024), the Cultivate Major Projects of Sichuan Province (14CZ0016), the Open Foundation of Microbial Resources and Drug Development of Key Laboratory and of Guizhou Province (GZMRD-2014-002), and the Doctor Startup Foundation Project of China West Normal University (11B019 and 11B020).

\section{References}

1. Hibbett DS, Binder M, Bischoff JF, Blackwell M, Cannon PF, Eriksson OE, Huhndorf S, James T, Kirk PM, Lücking R, et al: A higher-level phylogenetic classification of the Fungi. Mycol Res 111: 509-547, 2007.

2. Bertozzi CR and Kiessling LL: Chemical glycobiology. Science 291: 2357-2364, 2001.

3. Wasser SP: Medicinal mushrooms as a source of antitumor and immunomodulating polysaccharides. Appl Microbiol Biotechnol 60: 258-274, 2002.

4. Borchers AT, Stern JS, Hackman RM, Keen CL and Gershwin ME: Mushrooms, tumors, and immunity. Proc Soc Exp Biol Med 221: 281-293, 1999.

5. Rudd PM, Elliott T, Cresswell P, Wilson IA and Dwek RA: Glycosylation and the immune system. Science 291: 2370-2376, 2001.

6. Angeli JP, Ribeiro LR, Gonzaga ML, Soares SA, Ricardo MP, Tsuboy MS, Stidl R, Knasmueller S, Linhares RE and Mantovani MS: Protective effects of $\beta$-glucan extracted from Agaricus brasiliensis against chemically induced DNA damage in human lymphocytes. Cell Biol Toxicol 22: 285-291, 2006.

7. Li SP, Zhao KJ, Ji ZN, Song ZH, Dong TT, Lo CK, Cheung JK, Zhu SQ and Tsim KW: A polysaccharide isolated from Cordyceps sinensis, a traditional Chinese medicine, protects PC12 cells against hydrogen peroxide-induced injury. Life Sci 73: 2503-2513, 2003.

8. Wang F, Hou Y, Ding X, Hou W, Song B, Wang T, Li J and Zeng Y: Structure elucidation and antioxidant effect of a polysaccharide from Lactarius camphoratum (Bull.) Fr. Int J Biol Macromol 62: 131-136, 2013.

9. Staub AM: Removal of protein - Sevag method. Methods Carb Chem 5: 5-6, 1965.

10. Dubois M, Gilles KA, Hamilton JK, Rebers PA and Smith F: Colorimetric method for determination of sugars and related substances. Anal Chem 28: 350-356, 1956.

11. Yamamoto Y, Nunome T, Yamauchi R, Kato K and Sone Y: Structure of an exocellular polysaccharide of Lactobacillus helveticus TN-4, a spontaneous mutant strain of Lactobacillus helveticus TY1-2. Carbohydr Res 275: 319-332, 1995.

12. Yu RM, Yin Y, Yang W, Ma W, Yang L, Chen X, Zhang Z, Ye B and Song L: Structural elucidation and biological activity of a novel polysaccharide by alkaline extraction from cultured Cordyceps militaris. Car Poly 75: 166-171, 2009.

13. Partridge SM: Aniline hydrogen phthalate as a spraying reagent for chromatography of sugars. Nature 164: 443-446, 1949.
14. Dong Q, Zhang ZY, Lin Y and Fang J: Studies on two polysaccharides from Stephania tetrandra. Acta Biochim Biophys Sin 27: 261-265, 1995

15. Chen Y, Xie MY, Nie SP, Li C and Wang YX: Purification, composition analysis and antioxidant activity of a polysaccharide from the fruiting bodies of Ganoderma atrum. Food Chem 107: 231-241, 2008 .

16. Hakomori S: A rapid permethylation of glycolipid, and polysaccharide catalyzed by methylsulfinyl carbanion in dimethyl sulfoxide. J Biochem 55: 205-208, 1964.

17. Braca A, De Tommasi N, Di Bari L, Pizza C, Politi M and Morelli I: Antioxidant principles from Bauhinia terapotensis. J Nat Prod 64: 892-895, 2001.

18. Ye H, Wang KQ, Zhou CH, Liu J and Zeng X: Purification, antitumor and antioxidant activities in vitro of polysaccharides from the brown seaweed Sargassum pallidum. Food Chem 111: 428-432, 2008

19. Auddy B, Ferreira M, Blasina F, Lafon L, Arredondo F, Dajas F, Tripathi PC, Seal T and Mukherjee B: Screening of antioxidant activity of three Indian medicinal plants, traditionally used for the management of neurodegenerative diseases. J Ethnopharmacol 84: 131-138, 2003.

20. Cao W, Li XQ, Liu L, Wang M, Fan HT, Li C, Lv Z, Wang X and Mei Q: Structural analysis of water-soluble glucans from the root of Angelica sinensis (Oliv.) Diels. Carbohydr Res 341: 1870-1877, 2006.

21. Barker SA, Bourne EJ, Stacey M and Whiffen DH: Infra-red spectra of carbohydrates. Part I. Some derivatives of D-glucopyranose. J Chem Soc Chem Commu 171-176, 1954.

22. Kim YT, Kim EH, Cheong C, Williams DL, Kim CW and Lim ST: Structural characterization of $\beta$-D- $(1 \rightarrow 3,1 \rightarrow 6)$-linked glucans using NMR spectroscopy. Carbohydr Res 328: 331-341, 2000.

23. Wu XM and Tu PF: Isolation and characterization of $\alpha-(1 \rightarrow 6)$ glucans from Cistanche deserticola. J Asian Nat Prod Res 7: 823-828, 2005 .

24. Wang ZJ, Luo DH and Liang ZY: Structure of polysaccharides from the fruiting body of Hericium erinaceus Pers. Carbohydr Polym 57: 241-247, 2004.

25. Basu S, Liu Q, Qiu Y and Dong F: Gfi-1 represses $C D K N 2 B$ encoding $15^{\mathrm{INK} 4 \mathrm{~B}}$ through interaction with Miz-1. Proc Natl Acad Sci USA 106: 1433-1438, 2009.

26. Nishisho I, Nakamura Y, Miyoshi Y, Miki Y, Ando H, Horii A, Koyama K, Utsunomiya J, Baba S and Hedge P: Mutations of chromosome 5q21 genes in FAP and colorectal cancer patients. Science 253: 665-669, 1991 .

27. Yokota T, Arai N, Lee F, Rennick D, Mosmann T and Arai K: Use of a cDNA expression vector for isolation of mouse interleukin 2 cDNA clones: Expression of T-cell growth-factor activity after transfection of monkey cells. Proc Natl Acad Sci USA 82: 68-72, 1985.

28. Cerretti DP, McKereghan K, Larsen A, Cantrell MA, Anderson D, Gillis S, Cosman D and Baker PE: Cloning, sequence, and expression of bovine interleukin 2. Proc Natl Acad Sci USA 83: 3223-3227, 1986.

29. Mott HR, Driscoll PC, Boyd J, Cooke RM, Weir MP and Campbell ID: Secondary structure of human interleukin 2 from 3D heteronuclear NMR experiments. Biochemistry 31: 7741-7744, 1992. 